\title{
Developing reading in a first-year academic literacy course
}

\author{
Arlys L van Wyk and Willfred J Greyling \\ University of the Free State, P.O.Box 339, Bloemfontein, South Africa \\ vwyka.hum@ufs.ac.za \\ greywj.hum@ufs.ac.za
}

\section{Introduction}

Current South African government policies have obliged tertiary institutions to deal constructively with the needs of under-prepared incoming students (Department of Education 1997: 22). Access to tertiary education is currently more flexible than previously and is spurred by government grants and student loans. More students who do not meet the basic admission requirements are currently entering universities by means of bridging and extended programmes. The onus is on tertiary institutions to develop the skills of such students by means of academic development programmes (Yeld 2001: 6). Without the necessary language proficiency, these students remain at risk (Daly and Brown 2007: 2).

The English Academic Language Course presented at the University of the Free State aims to develop students' skills in reading academic texts and their ability to write logically and express themselves clearly. This paper focuses on the reading component of the course. To emphasise the crucial role played by reading proficiency when it comes to tertiary education access, one must note the important competencies required by the tertiary student.

Cliff and Yeld (2006) argue that student success in higher education studies can only be achieved if students are adequately equipped to - 
separate the point of an argument from its supporting detail; interact vigorously and critically with ideas in text and elsewhere; produce well-reasoned arguments supported by appropriate evidence; perceive the structure and coherence of a text, as well as the organisation of ideas that contributes to that structure; and understand that learning involves negotiating meaning, applying insights in different contexts, developing a view of one's own, and "seeing" the world differently as a consequence of these.

(Cliff and Yeld 2006: 22)

It is clear from the above that the ability to read academic texts stands central to achieving academic success (Day and Bamford 1998: 44).

\section{Theoretical underpinnings}

The present study takes the successful reader as the benchmark, on the basis of the argument that the successful reader needs language knowledge, background knowledge, cognitive thinking ability, and metacognitive thinking ability (Carrell 1988: 241; Alderson 1984: 1; Grabe and Stoller 2002: 12) to engage successfully in academic reading.

\subsection{Language knowledge}

The phrase "language knowledge" refers to organisational knowledge, which encapsulates grammatico-syntactic and textual knowledge as well as pragmatic knowledge, which in turn encompasses functional and sociolinguistic knowledge (Bachman and Palmer 1996). Specifically, our emphasis was on vocabulary, discourse, and contextualised grammatical knowledge, as well as on coherence processing in the context of pragmatic-textual competence. In the first-year module in question, each one of these has implications for the reading classroom where these competencies are systematically taught and fostered so as to encourage the strategic reading of texts.

Vocabulary knowledge is "critical not only for reading but also for all [second language] skills, for academic performance and for related background knowledge" (Grabe and Stoller 2002: 76). Successful readers of academic texts need to know approximately $95 \%$ of words 
found in most academic texts to be able to access the text (Chall and Jacobs 1996: 38; Grabe and Stoller 2002: 79). Many second language (L2) readers know the primary meanings of words but often do not know the secondary meanings, connotations or derivations; thus knowledge of words and their variety of possible meanings in a text are associated with conceptual knowledge and knowledge of the world (Carrell 1988: 240; Koda 2004: 71). Discourse knowledge requires the L2 reader to understand the text structure and the devices that knit discourse and signal sequences in texts, such as cause-effect, comparison, and contrast (Goldman and Rakestraw 2000: 325; Grabe and Stoller 2002: 80).

L2 readers of English often struggle with connective devices in texts such as anaphoric referencing, substitution, and signal words or discourse markers (Carrell 1988: 241; Cohen, Glasman, Rosenbaum-Cohen, Ferrara and Fine 1988: 158; Jordan 1997: 14; Grabe and Stoller 2002: 80). Any programme of reading that aims to develop strategic readers has to focus on systematic processing of these textual features. Grabe and Stoller (2002) refer to the lack of focus that this receives in reading programmes as an instructional dilemma: "few reading curricula focus on text structure and discourse organisation as consistent components of instruction" (Grabe and Stoller 2002: 76). Carrell (1988: 241) states that such regular instruction raises the L2 reader's awareness of how these cohesive devices unify ideas in a text. Instruction should therefore include activities focused on anaphoric and cataphoric referencing, the use of discourse markers, substitution, and general textual organisation consistent with a text-linguistic approach.

\subsection{Background knowledge}

Key to any reader's fluency is the background knowledge s/he adds to the text. "The construction of meaning depends on the reader's knowledge of the language, the (discursive) structure of texts, a knowledge of the subject of the reading and a broad-based background or world knowledge" (Day and Bamford 1997: 14). Readers who come from a print-poor background often have little understanding of print conventions, text genres and how these different texts are organised. A schema or abstract knowledge structure helps to scaffold new textual encounters and thus facilitates understanding (Ruddell 1994: 416; Koda 2004: 136). Often the schemata required to comprehend academic texts are not familiar to certain cultures and therefore do not form part of the L2 reader's world knowledge. Most fluent readers gain this crucial world knowledge through reading, which means that a good reading programme 
should focus on wide reading of texts to develop the world knowledge needed (Harris and Sipay 1990: 533).

\subsection{Cognitive thinking ability}

Cognitive thinking ability is another essential factor for reading comprehension and involves the following skills, according to Dubin, Eskey and Grabe (1986: 38-39):

- $\quad$ fitting new incoming information into existing information;

- noticing, understanding, and integrating meaningful relationships within the text;

- $\quad$ distinguishing the important from the trivial;

- $\quad$ determining the main idea;

- $\quad$ recognising and evaluating supporting information;

- $\quad$ separating fact from opinion;

- $\quad$ detecting the author's purpose or bias;

- $\quad$ evaluating the soundness of generalisations;

- $\quad$ detecting hidden assumptions, values, beliefs and attitudes; and

- $\quad$ analysing the logic and relevance of arguments.

Thus, systematic teaching of these skills is essential in order that the L2 reader may develop into a strategic reader.

\subsection{Metacognitive awareness}

Metacognitive awareness too should be a focus of a good L2 reading programme (Grabe and Stoller 2002: 45). Metacognitive awareness includes the following:

- monitoring one's understanding;

- $\quad$ locating the source of any comprehension breakdowns (language, background knowledge, thinking, or just poorly written text); and

- $\quad$ repairing the breakdown 
Being a fluent reader entails having knowledge (declarative knowledge), but also knowing how to use that knowledge (procedural knowledge) (Grabe and Stoller 2002: 46). Several researchers caution that one cannot draw distinct lines between linguistic and metalinguistic knowledge, or between cognitive knowledge and metacognitive knowledge (Urquhart and Weir 1998: 180; Bialystok 2001: 177; Grabe and Stoller 2002: 46). An integrated approach should therefore be taken to the teaching of these skills.

The above theoretical underpinnings have pedagogical implications which are reflected in the reading curriculum of the Academic Language Course of the reading course discussed below.

\section{The academic reading component}

The English Academic Language Course upon which the present study focuses is a one-year generic academic reading and writing course for first-year students who failed to achieve the required score of 50\% on the Placement Test in English for Educational Purposes (PTEEP) of the University of Cape Town. The reading component consists of three main sections, namely extensive reading, intensive reading and vocabulary study. The course content has been broadly aligned with the PTEEP test specifications (cf. Yeld 2003: 49).

The extensive reading component is an important focus of the reading programme, and requires that students read 100 pages per week from graded readers. These readers cover a wide range of interesting topics which aim at building general knowledge and providing the student with reading material at a level that is comprehensible to him/her. Students are tested by means of a diagnostic test ${ }^{1}$ to determine at which level they start their reading and they then scaffold themselves up a level every term.

The intensive reading programme is the component that is done in class where the focus is on authentic academic texts across a wide range of disciplines. Classroom activities focus on those features of the text that cause L2 readers difficulty, as outlined in section 2 above. Features such as discourse markers and anaphoric relations are explored, while students practise their cognitive and metacognitive strategies. Pre-reading strategies to build background knowledge and prepare students for reading are practised before reading every text. Much time is spent during the pre-reading phase of instruction on top-down processing 
skills so as to develop schemata and world knowledge. Most of our students fall into the low intermediate and intermediate reading levels (Van Wyk 2007: 355). Scoring levels are based on the International English Testing System (IELTS) band scale with "low intermediate" indicating a limited proficiency and "intermediate" indicating a modest proficiency level. We aim to develop their reading proficiency to the required advanced level before the end of the academic year. Students write a response to each graded reader they have read, and their contributions are subject to continuous assessment. Thus, the course aims to simulate the academic communicative tasks as they occur, which implies that reading comes first and is followed by writing. Reading and writing are taught as two sides of the same coin; learning to read is also learning to write, and vice versa.

The third and final component of the reading course is the vocabulary building section. Students study selected academic words as they appear in the context of the reading passages, and are quizzed on these every week. A large proportion of classroom time is devoted to teaching words/concepts and word derivations, connotations, primary and secondary meanings, as well as word functions.

For purposes of the present study, a small-scale experiment was run using a pre-experimental research design ${ }^{2}$ (with no control group) to establish whether students on the course had benefited from the intervention. The experiment and results are discussed below.

\section{Research method}

\subsection{A small-scale intervention}

In 2006, the Department of English at the University of the Free State undertook, as part of its quality-assurance programme for the year, to assess the pretest and posttest levels of proficiency of first-year students who were identified as vulnerable from an academic literacy perspective, and who were selected on the basis of their performance on the University of Cape Town's PTEEP to register for ALM104. A pretest-posttest analysis of the language proficiency scores of vulnerable students was performed using the same test. The test was deemed appropriate as its designers have reported reliability coefficients ranging from 0.89 to 0.91 for the same target population of students. 


\subsection{Duration of the intervention}

The intervention in the course ALM104 lasted for fourteen weeks ( $3 \frac{1}{2} 2$ months). The intervention took place during the following times: Two weeks in April 2006, three weeks in May 2006, two weeks in July 2006, four weeks in August 2006, and three weeks in September 2006 (when the PTEEP test was taken again as the posttest measure).

\subsection{Selection criteria}

The criterion to qualify as a vulnerable student and form part of the test group was a score of $49 \%$ or lower. Students scoring $50 \%$ and higher were deemed to be adequately literate in the academic domain to pursue their studies. Having selected the vulnerable group on the basis of this norm, we argue that the approach could be seen as a variation of what has been referred to in counseling literature as a "normative comparison". We are nonetheless aware that this approach, without a control group, may be deemed a pre-experimental approach, and therefore problematic in terms of both internal and external validity (cf. Huysamen 2001: 51$52)$.

\subsection{Nature of the intervention}

Students were exposed to an extensive (out-of-class) reading programme, pitched at their level of proficiency. In addition, students were exposed to intensive reading during in-class activities. Extensive reading was used to prompt students to access comprehensible input (following Krashen's (1982) and Krashen and Terrell's (1983) notion of comprehensible input at level $\mathrm{i}+1$ ), while intensive reading derives from the input-processing model of Van Patten (2002), and the output model of Gass (1997), the intention being to work within Gass's (1997) integrative model of language acquisition, as outlined in Block (2003). In addition, we argue that a normative comparison of the kind used in this study is consistent with Sternberg and Grigorenko's (2002: 5-8) developing expertise model, which requires that testing, test specifications, learning outcomes, interventions, assessments and eventual outcomes (i.e., posttest scores) are intimately related, and should therefore be aligned, as suggested in the context of dynamic testing.

\subsection{Research hypotheses}

The present study aimed to test the following hypotheses: 
Null-hypothesis: There is not a significant difference in the means obtained by the sample of students on their paired pretest and posttest scores on the PTEEP.

Alternate hypothesis: There is a significant difference in the means obtained by the sample of students on their paired pretest and posttest scores on the PTEEP.

\subsection{Statistical test and measures}

A paired t-test was selected for the purposes of this study, and the Excel data-base was imported into the Statistical Analysis System (SAS). The paired t-test was performed within the programme, and the programme outputs are reported below. We note the limitations of this choice of test, especially the threats to external and internal validity (Hatch and Lazaraton 1991: 287-290; Huysamen 2001: 51-52). As stated above, we did not reject out of hand the paired t-test as a relevant measure to establish whether students' proficiency had developed significantly. We argue that these findings suggest that we should pursue a more comprehensive approach with an experimental design.

\section{Results}

The SAS Enterprise Guide output appears in table 1, which captures the details of the cohort of vulnerable students' performance in the initial testing session ("1 $1^{\text {st }}$ Test") and the postintervention test ("2 $2^{\text {nd }}$ Test").

\begin{tabular}{|l|l|}
\hline Statistical measure & Value \\
\hline Mean of $1^{\text {st }}$ test & 36.87 \\
\hline Mean of $2^{\text {nd }}$ test & 45.96 \\
\hline Standard deviation for $1^{\text {st }}$ test & 8.37 \\
\hline Standard deviation for $2^{\text {nd }}$ test & 10.83 \\
\hline
\end{tabular}

Table 1. Means and standard deviations for the pretest and posttest scores of the vulnerable cohort of students

As undertaken at the outset, a paired t-test was performed to establish whether a statistically significant difference in students' academic literacy scores was evident. The statistical 
findings generated by the SAS programme for the paired t-test appear in table 2. Further analysis of these findings appears in table 3.

\section{T-Tests}

\begin{tabular}{|l|l|l|l|}
\hline Difference & DF & t Value & Pr $>t$ \\
\hline $2^{\text {nd }}$ Test $-1^{\text {st }}$ Test & 252 & 16.66 & $<.0001$ \\
\hline
\end{tabular}

Table 2. T-Test Results

\begin{tabular}{|l|c|}
\hline Statistical measure & \% of population \\
\hline $\begin{array}{l}\text { \% of vulnerable students whose academic literacy scores improved } \\
\text { from pretest to posttest }\end{array}$ & 85.4 \\
\hline $\begin{array}{l}\% \text { of students whose improvement in academic literacy scores } \\
\text { exceeded the standard deviation of } 8.37 \text { on the pretest }\end{array}$ & 53.1 \\
\hline$\%$ of students whose posttest scores were equal to or above 50 \% & 36.2 \\
\hline
\end{tabular}

Table 3. Three measures of students' language development

Figures 1 and 2 are given for the sake of comprehensiveness, illustrating the distribution of the vulnerable students' scores for both the pretest and the posttest. These results indicate that a significant shift in academic literacy competency had indeed occurred during the course of the year.

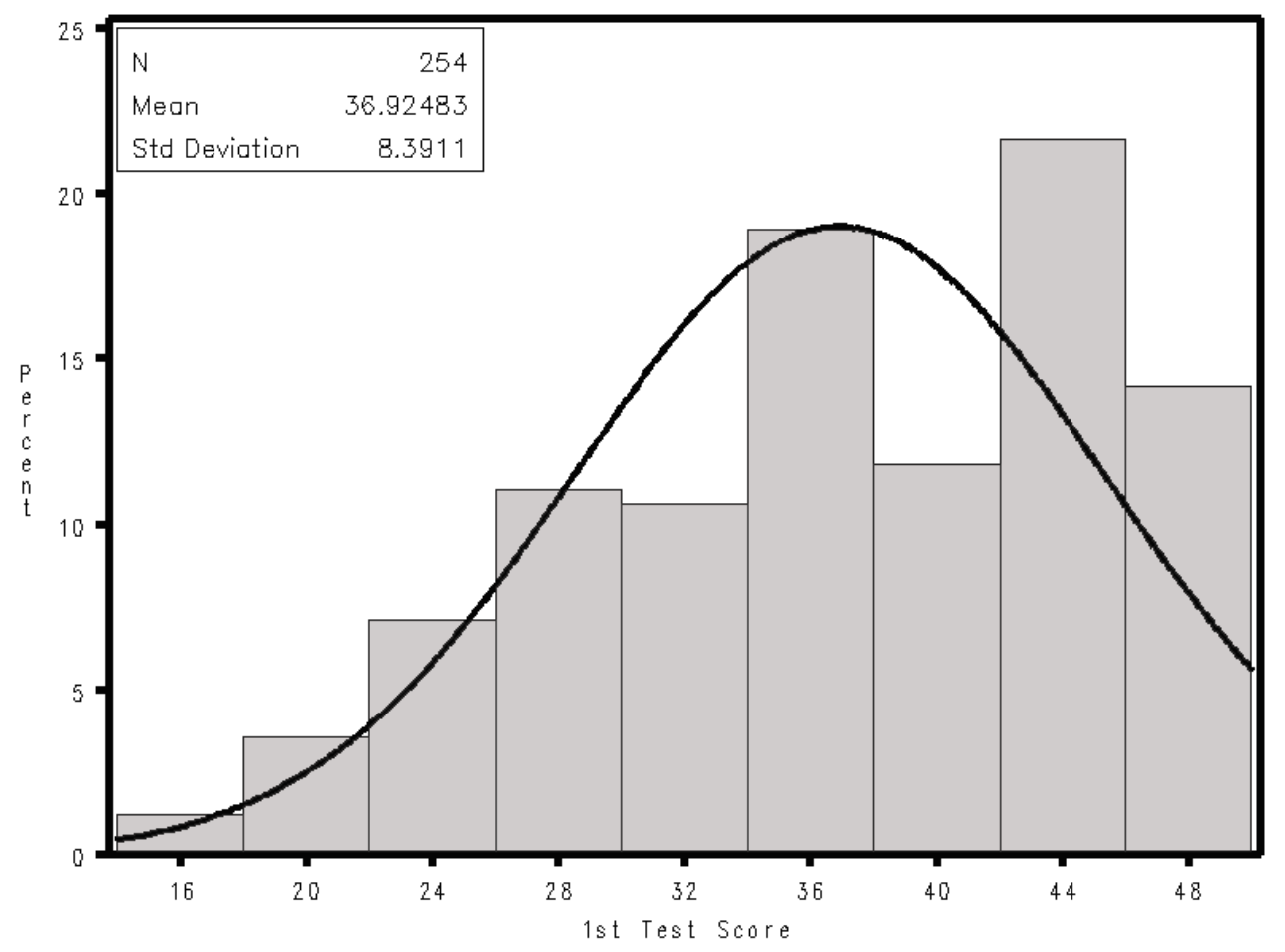

Figure 1. Distribution analysis: $1^{\text {st }}$ Test scores for vulnerable group [ $1^{\text {st }}$ test scores $\mathrm{x} \%$ of sample] 


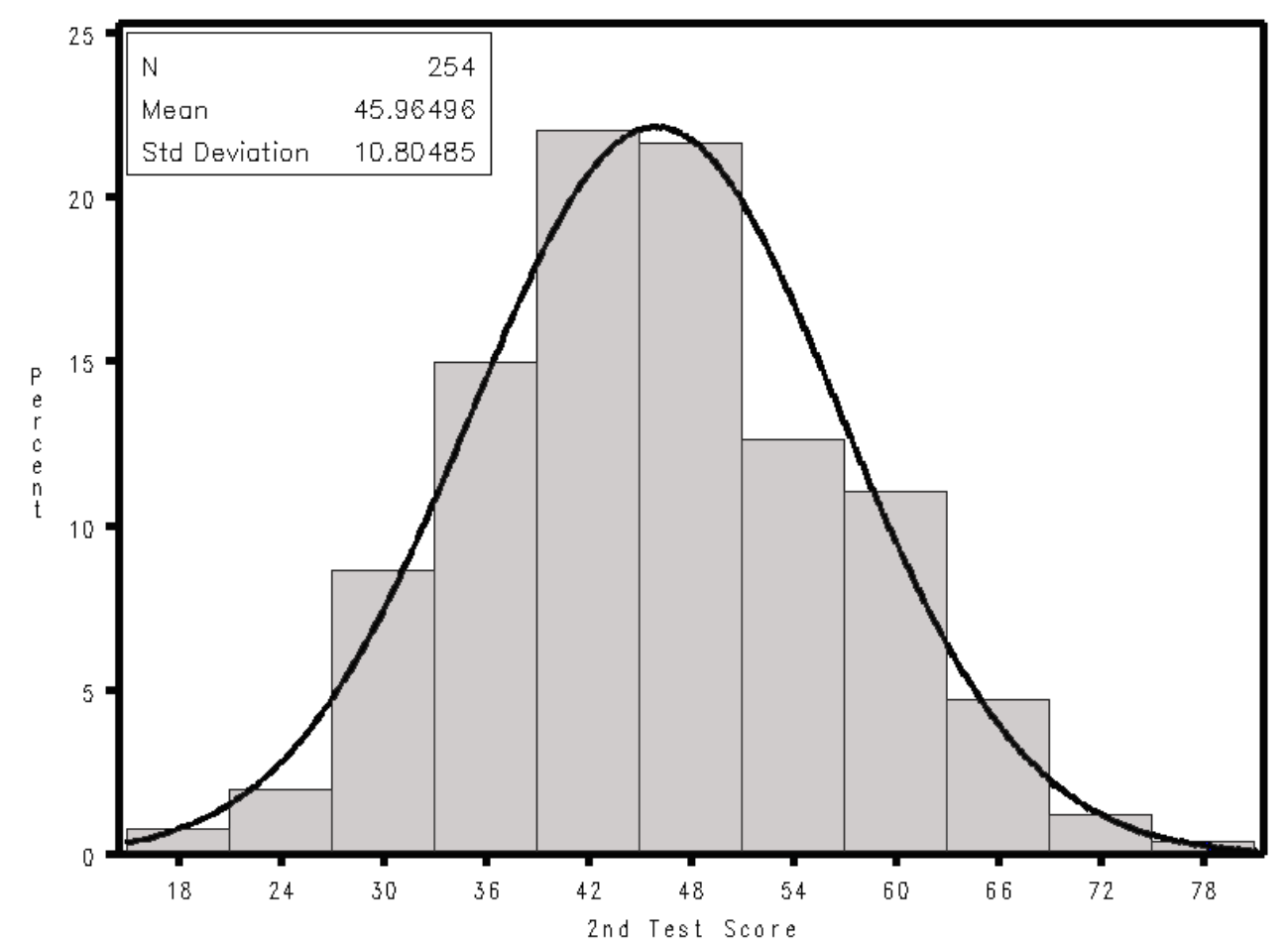

Figure 2. Distribution analysis: $2^{\text {nd }}$ Test scores for vulnerable group $\left[2^{\text {nd }}\right.$ test scores $\mathrm{x} \%$ of sample]

\section{Discussion}

\subsection{Results}

At first sight the results suggest that the null-hypothesis may be rejected: a statistically significant difference was found between the means of the students' pretest and posttest PTEEP scores. There is a probability of error of $0.1 \%$ if we claim that a significant difference in means obtains between the two sets of scores (cf. figure 2). However, the important question is whether this difference is significant in practical terms. In order to investigate this question, we performed univariate statistical analyses to shed light on the nature and scope of the difference in means.

Upon initial testing, student scores in the so-identified vulnerable group yielded a mean of 36.87 , and a standard deviation of 8.37. Thus, the students' scores were concentrated within the range from 28.5 (lower limit) to 45.2 (upper limit). At the second testing, their scores yielded a mean of 45.96 , and a standard deviation of 10.83 . Thus, the scores for the second test (i.e., after an intervention of 14 weeks) were concentrated in the range from 35.13 (lower limit) to 56.79 (upper limit). On the basis of these findings, we conclude that, on average, the 
students' academic literacy had developed to within four percent of that of the student population (observed mean on the PTEEP Test $2=45.96 \%$, initial cut-off of $50 \%$ ) (cf. figure 1), almost achieving the norm used for identifying students who were not deemed to need the intervention.

We argue that the intervention may be partly responsible for a significant number of students developing their literacy above the initial cut-off score of $50 \%$. A total of $36.2 \%$ of the vulnerable cohort of students scored $50 \%$ or higher (92 out of 254), and approximately $53.1 \%$ of them (approximately 135 out of 254 in the sample) scored a mark equal to or higher than the upper limit of the standard deviation on the $1^{\text {st }}$ test $(36.87+8.37=45.20)$. Interestingly, $85.4 \%$ of the cohort recorded an improved mark on the posttest (cf. table 3). These shifts are also captured graphically in the pretest and posttest distributions in Tables 1 and 2.

\subsection{Weaknesses of this analysis}

A pretest-posttest design constitutes a pre-experimental research design. Its main limitation is that one does not know whether the difference is due to the intervention or other factors (such as natural development). Thus, the fact that we did not control for natural growth (for example, by testing a similar group of first-year students exposed to first-year studies, but not to ALM104) is a limitation. The present findings are thus taken to indicate the need for a further study, with a fully-fledged experimental design, although it is difficult to imagine that such a group can indeed be found, and the question arises of how sample matching can be carried out without compromising on ethics in a real-life situation of this kind. The answer may be to alternate the interventions so that both the experimental and the control group experience the effects. Another possibility may be to explore the usefulness of normative comparisons, used in the therapeutic context, to measure and describe the effects of interventions in language development (cf. note 2).

\section{Conclusions}

Our conclusion is that there is adequate reason to believe that the extensive/intensive reading intervention played a significant role in precipitating growth in the academic literacy of the target population (amidst other factors, such as natural growth due to, among others, students' 
exposure to extensive reading of textbooks in the subjects they took). The recorded growth occurred after only $3 \frac{1}{2} 2$ months of the intervention.

We also point out that language development is a high-stakes activity in the higher education sector. For this reason, we have to be certain that our interventions are monitored and that we record substantive evidence of their success. At the same time, language testing is a highstakes activity, which implies that any instrumentation used in the process should be adequately reliable and valid for the purpose for which it is being used. Furthermore, we need to align the constructs tested by these instruments, and encapsulated in the test specifications of these tests, with the content in our language development modules. Alignment therefore involves much more than synchronising learning outcomes, lesson outcomes, materials, activities and assessment practices; it requires that the key constructs tested by language tests are aligned with the preceding components.

In our own current context, we recommended that -

- the ALM104 course become a research site where action research projects may be launched to tweak and refine the course so that informed decisions may be taken about teaching materials, teaching strategies, and assessment;

- the facilitator-manager of the language development projects consistently reflect on the training of tutors whose actions (i.e., teaching skills, strategies and assessment) impact on the academic literacy development of the vulnerable ALM104 cohort (i.e., pursuing constructive alignment and improvement in students' academic literacy skills);

- the 2006 cohort of ALM104 students (i.e., all students who took the test) be followed up to see to what extent the initial score on the PTEEP correlates with PASS/FAIL of the first and later years of study; and

- $\quad$ the study be replicated, closely following the requirements of an experimental design.

\section{Notes}

1. The UFS Department of English and the Kovsie Counselling Services, in collaboration with Karel Esterhuyse from the Department of Psychology, developed the UFS 
Language Proficiency Test as a diagnostic and placement test. Its test specifications focus on text-processing skills, while its reliability index for a first-year cohort of 1800 students was 0.86 (alpha coefficient) with a correlation of 0.84 with UCT's PTEEP.

2. Ideally, we would have embarked upon an experimental design, setting up control and experimental groups. However, it should be noted that in the therapeutic counselling context, we encountered a step-by-step outline of a pretest-posttest design, based on normative comparisons for treatment-outcome paradigms (Jacobson, Roberts, Berns and McGlinchey 1999; Kendall, Marrs-Garcia, Nath and Sheldrick 1999), which could be utilised profitably in this context. Note also the dynamic testing for the pretestposttest designs to be used to gauge the developing expertise of the individual student. Although these designs are pre-experimental, and at best quasi-experimental (cf. Huysamen 2001: chapter 7), we acknowledge that an experimental study is indicated for follow-up.

\section{References}

Alderson, J.C. 1984. Reading in a foreign language: A reading problem or a language problem? In J.C. Alderson and A.H. Urquhart (eds). Reading in a foreign language. London: Longman.

Bachman, L.F. and A.S. Palmer. 1996. Language testing in practice. Hong Kong: Oxford University Press.

Bialystok, E. 2001. Metalinguistic aspects of bilingual processing. Annual Review of Applied Linguistics 21: 169-181.

Block, D. 2003. The social turn in second language acquisition. Edinburgh: Edinburgh University Press.

Carrell, P.L. 1988. Interactive text processing: Implications for ESL/second language reading classrooms. In P.L. Carrell, J. Devine and D.E. Eskey (eds). Interactive approaches to second language reading. New York: Cambridge University Press.

Chall, J.S. and V.A. Jacobs. 1996. The reading, writing, and language connection. In J. Shimron (ed). Literacy in education: Essays in memory of Diana Feitelson. Cresskill: Hampton Press.

Cliff, A. and N. Yeld. 2006. Domain 1 - Academic literacy. In Access and entry level benchmarks. Pretoria: A HESA publication. pp. 19-23 
Cohen, A., H. Glasman, P.R. Rosenbaum-Cohen, J. Ferrara and J. Fine. 1988. Reading English for specialized purposes: Discourse analysis and the use of student informants. In P.L. Carrell, J. Devine and D.E. Eskey (eds). Interactive approaches to second language reading. New York: Cambridge University Press.

Daly, A. and J. Brown. 2007. Lecturer communication in a multicultural higher education context. Proceedings of the ISANA International Conference: Student success in international education, Adelaide, Australia.

Day, R.R. and J. Bamford. 1998. Extensive reading in the second language classroom. Cambridge: Cambridge University Press.

Department of Education. 1997. Education white paper. A programme for higher education transformation. http://education.pwv.gov.za/index.asp?src=docuandxsrc=legi. Accessed on 3 September 2003.

Dubin, F., D.E. Eskey and W.Grabe. 1986. Teaching second language reading for academic purposes. Reading, Massachusetts: Addison-Wesley Publishing.

Goldman, S.R. and J.A. Rakestraw, Jr. 2000. Structural aspects of constructing meaning from text. In M.L. Kamil, P.B. Mosenthal, P.D.Pearson and R. Barr (eds). Handbook of reading research. pp. 311-335.

Grabe, W. and F.L. Stoller. 2002. Teaching and researching reading. Harlow, Essex: Pearson Education.

Harris, A.J. and E.R. Sipay. 1990. How to increase reading ability: A guide to developmental and remedial methods. New York: Longman.

Hatch, E. and A. Lazaraton. 1991. The research manual: Design and statistics for applied linguistics. Massachusetts: Heinle and Heinle Publishers.

Huysamen, G.K. 2001. Methodology for the social and behavioural sciences. Oxford: Oxford University Press.

Jacobson, N.S., L.J Roberts, S.B. Berns and J.B. McGlinchey. 1999. Methods for defining and determining the clinical significance of treatment effects: Description, application, and alternatives. Journal of Counseling and Clinical Psychology 67(3): 300-307.

Jordan, R.R. 1997. English for academic purposes: A guide and resource book for teachers. Cambridge: Cambridge University Press.

Kendall, P.C., A. Marrs-Garcia, S.R. Nath and R. Sheldrick. 1999. Normative comparisons for the evaluation of clinical significance. Journal of Counseling and Clinical Psychology 67(3): 285-299. 
Koda, K. 2004. Insights into second language reading: A cross-linguistic approach. Cambridge: Cambridge University Press.

Krashen, S.D. and T.D. Terrell. 1983. The natural approach: Language acquisition in the classroom. Hayward: Alemany Press.

Ruddell, M.R. 1994. Vocabulary knowledge and comprehension: A comprehension-process view of complex literacy relationships. In R.B. Ruddell, M.R. Ruddell and H. Singer (eds). Theoretical models and processes of reading. Newark: International Reading Association.

SAS Enterprise Guide. 2005. Cary, North Carolina: SAS Institute, Inc.

Sternberg, R.J. and E.L. Grigorenko. 2002. Dynamic testing. The nature and measurement of learning potential. Cambridge: Cambridge University Press.

Urquhart, A. H. and J.C. Weir. 1998. Reading in a foreign language. London: Longman.

Van Wyk, A.L. 2007. Extensive graded reading as a means of bridging the divide to the authentic academic text. South African Journal of Higher Education 21(2): 346-359.

Van Patten, B. 2002. Processing instruction: An update. Language Learning 52: 755-803.

Yeld, N. 2001. Assessment, equity and language of learning: Key issues for higher education in South Africa. Doctoral dissertation, University of Cape Town.

Yeld, N. 2003. Academic literacy and numeracy profiles: An analysis of some results from the AARP and TELP tests of incoming students (2001/2002 entry years). In Into higher education - Perspectives on entry thresholds and enrolment systems. A joint SAUVCA-CTP publication. pp. 21-52. 